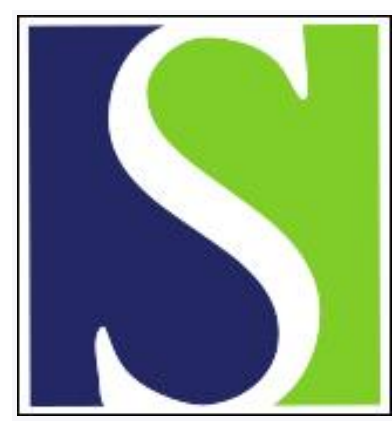

Scand J Work Environ Health 2003;29(3):167-169

https://doi.org/10.5271/sjweh.719

Issue date: Jun 2003

\title{
Are long workhours a health risk?
}

by Härmä $M$

Affiliation: Scandinavian Journal of Work Environment Health, Topeliuksenkatu 41 a A, FIN-00250 Helsinki, Finland. mikko.harma@ttl.fi

Refers to the following texts of the Journal: 2003;29(3):171-188 1997;23(6):403-413

The following article refers to this text: 2007;33(5):344-350

Key terms: editorial; health risk; long workhours

This article in PubMed: www.ncbi.nlm.nih.gov/pubmed/12828386

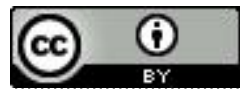




\section{Are long workhours a health risk?}

The way that we use our time has become more and more important. Changes in the economy and in information and communication technology have increased the speed of business processes. If the allocation of human resources and the timing of projects are not successful, the key persons in a company easily end up working overtime or under time pressure. According to the third European survey on work conditions, $29 \%$ of European employees work continuously to meet tight deadlines; $20 \%$ work 45 hours or more in a week, the percentage being higher for self-employed persons (1). About $13 \%$ of full-time employees work 51 hours or more a week (2), the number of hours being clearly higher than the 48-hour "maximum limit" established by the European directive on worktime (3). Occasional overtime is also common. In Finland, $57 \%$ of men and $42 \%$ of women worked overtime every month in 2000 (4).

Although the relationship between workhours and health has been studied for decades, most interest has been focused on the effects of night and shift work on health instead of on the effects of long workhours. In work psychology, the relationship between mental work demands and health has also been a popular topic. Instead of quantifying directly the actual length of the workweek (exposure), most psychosocial studies have used different questionnaires to ask for subjective perceptions of workload. In this issue of the Scandinavian Journal of Work, Environment \& Health, an update of the current knowledge on long workhours and health is the topic of one of the reviews (5). Moreover, the review examines the validity of two different pathways, insufficient recovery and poor life-style, which could possibly link long workhours with adverse health.

The review shows that long workhours are indeed associated with adverse health, in particular cardiovascular disease, disability retirement, subjectively measured poor health, and fatigue. The most interesting studies show that working more than 11 hours a day is associated with a three times higher risk of myocardial infarction (6) and about a four times higher risk of noninsulin-dependent diabetes (7), than that of a normal workday. Working 60 hours or more a week has also been found to be associated with an almost three times greater risk of disability retirement (8). The results thus indicate that long workhours are not only subjectively stressful but may also lead to higher morbidity. However, the number of studies concerning the different areas of health is still low. Only a single study was included on the areas of mortality (9) and noninsulin diabetes (6). Since new studies may have different results - like the recent negative finding between overtime and noninsulin-dependent diabetes (10) —we still must wait for the final conclusions.

The second question of the review focused on studying the evidence on physiological and behavioral changes related to long workhours. The evidence on cardiovascular physiological pathways proved to be rather weak in that only few studies indicated that extended workdays could be related to, for example, increased heart rate and blood pressure. Some occasional evidence was found for the relationship between long workhours and the depression of the immunologic system. No evidence was found on the possible association between long workhours and poor eating habits or physical inactivity.

The most consistent results were related to the inverse association between long workhours and sleep. Although there is no direct relationship between the length of the workweek and daily sleep, sleeping hours are remarkably shortened among those who work more than some 50 hours a week. The distorted 24-hour time structure is thus reflected in reduced sleep only at the very end of the normal distribution of workhours. 
It is easy to agree with the conclusion that short sleep hours due to a lack of insufficient recovery may be the most important pathway connecting extended workhours and adverse health. Short sleep hours (4-6 hours/day) have been shown to be associated with an increased risk of coronary heart disease when compared with normal sleep hours (7-8 hours/day) $(11,12)$. It is also well acknowledged that insufficient sleep can increase the activity of the sympathetic nervous system and lead to an increase in blood pressure and heart rate $(13,14)$. The experimental studies on partial sleep deprivation show that already 6 days with 4 hours of sleep a day changes the 24-hour cortisol profile, increases sympathetic activity, and decreases glucose tolerance among young healthy subjects (15). In a recent case-referent study, both long workhours ( $\geq 61$ hours/week) and short sleep ( $\leq 5$ hour/day) were associated with at least a two times higher risk of acute myocardial infarction (16). This study also showed that, when long workhours and insufficient sleep were combined, the risk of myocardial infarction was the highest.

It is possible that insufficient sleep could be the common pathway explaining not only the effects of long workhours on cardiovascular disease, but also some of the health effects of shift work (17) and sleep apnea (18). Since high job demands and stress are also risk factors for insomnia and sleep deprivation $(19,20)$, sleep debt could be one pathway through which mental workload and job stress can also increase the risk of cardiovascular disease. The relationship between job stress, long workhours and sleep can be complicated. The length of the workday and the effects of long workhours on sleep probably depend on job stress. Since only a few people have long workhours without job stress, it is also difficult to separate the physiological and behavioral mechanisms of the two.

In conclusion, the current review of van der Hulst (5) shows that we have good reason to be concerned about the possible adverse health effects of long workhours. More epidemiologic and physiological research is clearly needed to clarify the different effects and pathways connecting long workhours and health. Since short sleep and its physiological consequences proved to be a promising candidate for the pathway from insufficient recovery to adverse health, the role of sleep and especially long-term partial sleep deprivation should be investigated in more detail. It is also noteworthy to see that most of the epidemiologic studies on long workhours have been conducted in Japan, the country in which "karoshi", sudden death due to extremely long workweeks and insufficient sleep, was first recognized. Since the psychosocial and domestic factors - as well as the possible "triggering" level of long workhours on health-may depend on cultural factors, more studies are needed also in other countries to clarify the role of long workhours with respect to health. The ultimate goal is naturally the prevention of adverse health in relation to long workhours. For that purpose, we would benefit from additional information on the dose-response relationship between long workhours and health, and we should be aware of the critical factors — like job stress and sleep—-that can modify the final output.

\section{References}

1. Pascal P, Damien M. Third European survey on working conditions 2000. Luxembourg: European Foundation for the Improvement of Living and Working Conditions; 2001.

2. Bielenski H, Bolch G, Wagner A. Working time preferences in sixteen European countries. Luxembourg: European Foundation for the Improvement of Living and Working Conditions; 2002.

3. European Council. Concerning certain aspects of working time. Off J Eur Communities 1993;L307:18-24. Council directive 93/104/EC.

4. Kandolin I, Härmä M, Toivanen M. Flexible working hours and well-being in Finland. J Hum Ergol. In press.

5. van der Hulst M. Long workhours and health. Scand J Work Environ Health 2003;29:171-188.

6. Sokejima S, Kagamimori S. Working hours as a risk factor for acute myocardial infarction in Japan: case-control study. BMJ 1998;317:775-80.

7. Kawakami N, Araki S, Takatsuka H, Shimazu H, Ishibashi H. Overtime, psychosocial working conditions, and occurrence of non-insulin dependent diabetes mellitus in Japanese men. J Epidemiol Community Health 1999;53:359-63.

8. Krause N, Lynch J, Kaplan GA, Cohen RD, Goldenberg De, Salonen JT. Predictors of disability retirement. Scand J Work Environ Health 1997;23:403-13. 
9. Nylén L, Voss M, Floderus B. Mortality among women and men relative to unemployment, part time work, overtime work, and extra work: a study based on data from the Swedish twin registry. Occup Environ Med 2001;58:52-

10. Nakanishi N, Nishina K, Yoshida H, Matsuo Y, Nagano K, Nakamura K, et al. Hours of work and the risk of developing impaired fasting glucose or type 2 diabetes mellitus in Japanese male office workers. Occup Environ Med 2001;58(9):569-74.

11. Kripke DF, Simons RN, Garfinkel L, Hammond E. Short and long sleep and sleeping pills. Arch Gen Psychiatry 1979;36:103-16.

12. Partinen M, Putkonen PTS, Kaprio J, Koskenvuo M, Hilakivi I. Sleep disorders in relation to coronary heart disease. Acta Med Scand 1982;660:59-83.

13. Lusardi P, Zoppi A, Preti P, Pesce M, Piazza E, Fogari R. Effects of insufficient sleep on blood pressure in hypertensive patients: a 24-hour study. Am J Hypertens 1999;12:63-8.

14. Tochikubo O, Ideda A, Miyajima E, Ishii M. Effects of insufficient sleep on blood pressure monitored by a new multibiomedical recorder. Hypertension 1996;27:1318-24.

15. Spiegel K, Leproult R, Van Cauter E. Impact of sleep debt on metabolic and endocrine function. Lancet 1999;354:1435-9.

16. Liu Y, Tanaka H. Overtime work, insufficient sleep, and risk of non-fatal acute myocardial infarction in Japanese men. Occup Environ Med 2002;59:447-51.

17. Bøggild H, Knutsson A. Shift work, risk factors and cardiovascular disease. Scand J Work Environ Health 1999:25:85-99.

18. Koskenvuo M, Kaprio J, Telakivi T, Partinen M, Heikkilä K, Sarna S. Snoring as a risk factor for ischaemic heart disease and stroke in men. BMJ 1987;294:16-9.

19. Kalimo R, Tenkanen L, Härmä M, Poppius E, Heinsalmi P. Job strews and sleep disorders: findings from the Helsinki Heart Study. Stress Med 2000;16:65-75.

20. Åkerstedt T, Knutsson A, Westerholm P, Theorell T, Alfredsson L, Kecklund G. Sleep disturbances, work stress and work hours: a cross-sectional study. J Psychosom Res 2002;53:741-8.

Mikko Härmä, Editor in Chief

Scandinavian Journal of Work, Environment \& Health 


\section{Scandinavian Journal of Work, Environment \& Health}

The Scandinavian Journal of Work, Environment \& Health is an international scientific periodical which began publication in 1975. The Journal appears 6 times a year, at the end of February, April, June, August, October, and December. In addition 1 to 3 self-financed supplements on specific topics are generally published annually.

The circulation of the Journal is worldwide. By the end of 2002, the total distribution was about 1100 copies to approximately 45 countries on 5 continents. Most of the subscriptions came from the United States (184), The Netherlands (89), Italy (68), Canada (51), Finland (51), Great Britain (50), Germany (48), Norway (48), Sweden (43), Spain (33), Japan (31), Australia (28), Denmark (27), and France (27).

The Journal is open to all authors without regard to nationality. In 2002, the number of manuscripts submitted for publication in a regular issue was 192. In volume 28 , the first author of the 83 published articles (supplements included) was from Finland (25), Sweden (14), The Netherlands (10), the United States (9), Denmark (4), the United Kingdom (3), France (3), Germany (3), Norway (2), Canada (2), Spain (2), Switzerland (2), Japan (1), Korea (1), Argentina (1), and Turkey (1).

The acceptance rate of the 192 articles submitted in 2002 was $23 \%$ by the end of March 2003; at that time the decision was still pending for 28 of the manuscripts.

In a peer-review process, 1 to 4 referees independently evaluate the scientific quality of the submitted manuscripts. The Journal uses a double-blind peerreview system.

The elapsed time from submission to publication for the articles published in 2002 averaged 9 months. A decision of acceptance of a manuscript was reached in 1 to 3 months (average 7 weeks).

The Journal is indexed or abstracted in Current Contents, the Science Citation Index, Biological Abstracts, Excerpta Medica, CISDOCE HSELINE, TZXLIRE, NIOSHTIC, etc.

For the latest year available, 2001, the impact factor of the Journal was 1.590 . 